\title{
MAPK and JAK-STAT pathways dysregulation in plasmablastic lymphoma
}

Haematologica 2021

Volume 106(10):2682-2693

\section{Correspondence:}

ELIAS CAMPO

ecampo@clinic.cat

Received: September 24, 2020.

Accepted: March 31, 2021.

Pre-published: May 6, 2021.

https://doi.org/10.3324/haematol.2020.271957

(C)2021 Ferrata Storti Foundation

Material published in Haematologica is covered by copyright. All rights are reserved to the Ferrata Storti Foundation. Use of published material is allowed under the following terms and conditions:

https://creativecommons.org/licenses/by-nc/4.0/legalcode. Copies of published material are allowed for personal or internal use. Sharing published material for non-commercial purposes is subject to the following conditions:

https://creativecommons.org/licenses/by-nc/4.0/legalcode, sect. 3. Reproducing and sharing published material for commercial purposes is not allowed without permission in writing from the publisher.

\begin{abstract}
Joan Enric Ramis-Zaldivar,,${ }^{1,2^{\star}}$ Blanca Gonzalez-Farre, ${ }^{1,2^{\star}}$ Alina Nicolae, ${ }^{3}$ Svetlana Pack, ${ }^{3}$ Guillem Clot, ${ }^{1,2}$ Ferran Nadeu, ${ }^{1,2}$ Anja Mottok, ${ }^{4}$ Heike Horn, $,, 6,7$ Joo Y. Song, ${ }^{8}$ Kai Fu, ${ }^{9}$ George Wright, ${ }^{10}$ Randy D. Gascoyne, ${ }^{4}$ Wing C. Chan, ${ }^{8}$ David W. Scott,${ }^{4,11}$ Andrew L. Feldman, ${ }^{12}$ Alexandra Valera, ${ }^{1}$ Anna Enjuanes,${ }^{1,2}$ Rita M. Braziel, ${ }^{13}$ Erlend B. Smeland ${ }^{14,15}$ Louis M. Staudt, ${ }^{16}$ Andreas Rosenwald, ${ }^{17}$ Lisa M. Rimsza, ${ }^{18}$ German Ott, ${ }^{5,6,7}$ Elaine S. Jaffe, ${ }^{3}$ Itziar Salaverria ${ }^{1,2, *}$ and Elias Campo ${ }^{1,2,19, *}$ for the Leukemia and Lymphoma Molecular Profiling Project (LLMPP)
\end{abstract}

${ }^{1}$ Hematopathology Unit, Hospital Clínic of Barcelona, Institut d'Investigacions Biomèdiques August Pi i Sunyer (IDIBAPS), Barcelona, Spain; ${ }^{2}$ Centro de Investigación Biomédica en Red de Cáncer (CIBERONC), Madrid, Spain; ${ }^{3}$ Hematopathology Section, Laboratory of Pathology, National Cancer Institute, Bethesda, MD, USA; ${ }^{4}$ Department of Pathology and Laboratory Medicine, University of British Columbia, Vancouver, British Columbia, Canada; ${ }^{5}$ Department of Clinical Pathology, Robert-Bosch-Krankenhaus, Stuttgart, Germany; ${ }^{6}$ Dr. Margarete Fischer-Bosch Institute of Clinical Pharmacology, Stuttgart, Germany; ${ }^{7}$ University of Tübingen, Tübingen, Germany; ${ }^{8}$ Department of Pathology, City of Hope National Medical Center, Duarte, CA, USA; ' Department of Pathology and Microbiology, University of Nebraska Medical Center, Omaha, NE, USA; ${ }^{10}$ Biometric Research Branch, Division of Cancer Diagnosis and Treatment, National Cancer Institute, National Institutes of Health, Bethesda, MD, USA; ${ }^{11}$ Department of Medicine, University of British Columbia, Vancouver, British Columbia, Canada; ${ }^{12}$ Department of Laboratory Medicine and Pathology, Mayo Clinic, Rochester, MN, USA; ${ }^{13}$ Department of Clinical Pathology, Oregon Health \& Science University, Oregon, OR, USA; ${ }^{14}$ Department of Immunology and Centre for Cancer Biomedicine, University of Oslo, Oslo, Norway; ${ }^{15}$ Oslo University Hospital, Oslo, Norway; ${ }^{16}$ Lymphoid Malignancies Branch, Center for Cancer Research, National Institutes of Health, Bethesda, MD, USA; ${ }^{17}$ Institute of Pathology, University of Würzburg, Würzburg, Germany; ${ }^{18}$ Department of Laboratory Medicine and Pathology, Mayo Clinic, Phoenix, AZ, USA and ${ }^{19}$ University of Barcelona, Barcelona, Spain

*JER-Z and BG-F contributed equally as co-first atuhors.

"IS and EC contributed equally as co-senior atuhors.

\section{ABSTRACT}

P lasmablastic lymphoma (PBL) is an aggressive B-cell lymphoma with an immunoblastic/large-cell morphology and terminal B-cell differentiation. The differential diagnosis from Burkitt lymphoma, plasma cell myeloma and some variants of diffuse large B-cell lymphoma may be challenging because of the overlapping morphological, genetic and immunophenotypic features. Furthermore, the genomic landscape in $\mathrm{PBL}$ is not well known. To characterize the genetic and molecular heterogeneity of these tumors, we investigated 34 cases of PBL using an integrated approach, including fluorescence in situ hybridization, targeted sequencing of 94 B-cell lymphoma-related genes, and copy-number arrays. PBL were characterized by high genetic complexity including MYC translocations (87\%), gains of 1q21.1-q44, trisomy 7, 8q23.2q24.21, 11p13-p11.2, 11q14.2-q25, 12p and 19p13.3-p13.13, losses of $1 \mathrm{p} 33,1 \mathrm{p} 31.1-\mathrm{p} 22.3,13 \mathrm{q}$ and $17 \mathrm{p} 13.3-\mathrm{p} 11.2$, and recurrent mutations of STAT3 (37\%), NRAS and TP53 (33\%), MYC and EP300 (19\%) and CARD11, SOCS1 and TET2 (11\%). Pathway enrichment analysis suggested a cooperative action between $M Y C$ alterations and MAPK (49\%) and JAK-STAT (40\%) signaling pathways. Of note, Epstein-Barr virus (EBV)-negative PBL cases had higher mutational and copy-number load and more frequent TP53, CARD11 and MYC mutations, whereas EBVpositive PBL tended to have more mutations affecting the JAK-STAT pathway. In conclusion, these findings further unravel the distinctive molecular heterogeneity of PBL identifying novel molecular targets and the different genetic profile of these tumors in relation to EBV infection. 


\section{Introduction}

Plasmablastic lymphoma (PBL) is an aggressive lymphoid neoplasm characterized by a diffuse proliferation of large neoplastic cells with an immunoblastic or plasmablastic morphology but expressing a plasma cell phenotype including positivity for BLIMP1/PRDM1, XBP1, CD138, CD38, Vs38c and MUM1/IRF4 and negativity or weak positivity for CD45 and markers of mature B cells such as CD20 and PAX5. CD79a is positive in approximately $50-85 \%$ of the cases. ${ }^{1,2}$ This tumor was initially described as a subtype of diffuse large B-cell lymphoma (DLBCL) present in the oral cavity of patients positive for human immunodeficiency virus (HIV). Subsequent studies expanded the spectrum of presentation of this lymphoma to other extranodal sites and immunodeficient conditions such as iatrogenic immunosuppression associated with post-transplant therapy or chronic treatments for autoimmune diseases and aging. ${ }^{1,3,4}$

Epstein-Barr virus (EBV) is known to be an important element in the development of PBL, especially in HIV-positive patients, and can be detected in $60-75 \%$ of PBL cases by in situ hybridization. ${ }^{1,45}$ The role of EBV infection has been related to the anti-apoptotic effect in $B$ cells through several mechanisms related to EBV antigens. ${ }^{4}$ Around $50 \%$ of PBL carry immunoglobulin (IG)/MYC rearrangements, a hallmark of Burkitt lymphoma (BL). This rearrangement seems to be observed more frequently in EBV-positive than in EBV-negative PBL (74\% vs. 43\%).,4,7

Few studies have investigated the genetic landscape of PBL. Copy number profiling revealed that recurrent gains of 1p36, 1p36-p34, 1q21-q23, 7q11, 11q12-q13 and 22q12-q13 are common features of PBL. ${ }^{8}$ More recently a 34-gene targeted next-generation sequencing study highlighted PRDM1 and STAT3 as key genes in the pathogenesis of PBL in addition to $M Y C$. Furthemore, during the preparation of this manuscript, a genomic analysis of HIV-positive PBL patients from South Africa identified recurrent mutations in the JAK-STAT and RAS-MAPK signaling pathways and recurrent copy number alterations including large chromosomal gains of $1 \mathrm{q}$ and chr7 and focal gains in 6p22.1, 1q21.3 and $11 \mathrm{p} 13$ but the possible differential representation of these alterations in relationship to EBV infection could not be defined..$^{10} \mathrm{~A}$ gene expression profiling study has shown that, compared to DLBCL, PBL downregulates B-cell receptor signaling genes including transcriptionally activated targets of nuclear factor $\kappa \mathrm{B}(\mathrm{NF \kappa B})$ signaling and upregulation of $M Y B$ and $M Y C$ target genes. ${ }^{11}$

Some PBL share morphological and immunophenotypic features with other aggressive lymphoid neoplasias such as $\mathrm{BL}$, plasmablastic transformation of plasma cell myeloma (PCM) and some variants of DLBCL with immunoblastic features and/or activated B-cell like (ABC) cell of origin.,21,13 Of note, plasmablastic PCM has been associated with MYC translocations and worse prognosis, ${ }^{4,14}$ which adds difficulty to the already challenging differential diagnosis. The management of patients with PBL is still not standardized and most patients are treated with cyclophosphamide, doxorubicin, vincristine, and prednisone (CHOP) or CHOP-like regimens. However, responses are relatively poor with a median overall survival of about 1 year. ${ }^{1,3,15}$ More intensive regimens, such as infusional EPOCH, Hyper-CVAD, or CODOX-M/IVAC, have also been used without improving the prognosis. ${ }^{16}$ On the other hand, bortezomib, a proteosome inhibitor used in the treatment of PCM, has shown potential efficacy in PBL with promising early results. ${ }^{17}$
A better understanding of the genetic profiling of $\mathrm{PBL}$ may substantiate its distinction from other entities and may contribute to the design of novel therapeutic strategies. We performed a high-resolution genetic analysis of PBL to discover the hallmarks of this disease which may enhance greater diagnostic accuracy and provide insight into the clinical behavior of this lymphoma.

\section{Methods}

\section{Case selection and DNA/RNA extraction}

Thirty-four cases with a consensus diagnosis of PBL according to the World Health Organization (WHO) classification ${ }^{1}$ were obtained from the archives of the Hospital Clínic of Barcelona (Barcelona, Spain), the National Institutes of Health National Cancer Institute (Bethesda, USA) and the Department of Clinical Pathology, Robert-Bosch-Krankenhaus (Stuttgart, Germany). The cases were reviewed by the Leukemia and Lymphoma Molecular Profiling Project (LLMPP) pathology panel. Only cases with more than $50 \%$ neoplastic cells were included.

DNA and RNA from formalin-fixed paraffin-embedded material were extracted simultaneously using a Qiagen AllPrep DNA/RNA FFPE kit with Deparaffinization Solution (Qiagen Inc.), according to manufacturer's instructions. This study was approved by our Institutional Review Board. Informed consent was obtained from all patients in accordance with the Declaration of Helsinki.

\section{Immunohistochemistry and fluorescence in situ hybridization}

Immunohistochemical studies were performed using standard protocols. (Online Supplementary Table S1). Fluorescence in situ hybridization (FISH) analyses for the detection of $B C L 2, B C L 6$, $M Y C$ and IGH translocations were performed using standard techniques and commercial Dual Color Break-Apart Rearrangement Probes (Vysis, Abbott Molecular, Wiesbaden, Germany).

\section{Copy number analysis}

Copy number alterations were examined in 33 PBL samples using an Oncoscan FFPE Assay Kit (Thermo Fisher Scientific, Waltham, MA, USA) according to standard protocols. Gains and losses and copy number neutral loss of heterozygosity (CNNLOH) regions were evaluated using Nexus Biodiscovery 9.0 software (Biodiscovery, Hawthorne, CA, USA). The proportion of tumor cells or cancer cell fraction carrying each copy number alteration $\left(\mathrm{CCF}_{\mathrm{ou}}\right)$ was estimated from the B-allele frequency and corrected for the tumor cell content or purity of the sample obtained from ASCAT (Online Supplementary Methods). ${ }^{18}$ Copy number alterations were considered clonal if their $\mathrm{CCF}_{\text {cun }}$ was $\geq 85 \%{ }^{19}$ Previously published data from $35 \mathrm{BL}, 41 \mathrm{PCM}$ and $49 \mathrm{ABC}-$ DLBCL were used for comparisons. ${ }^{2023}$

\section{Mutational analysis}

Twenty-seven PBL were examined for the mutational status of 94 B-cell lymphoma-related genes (Online Supplementary Table S2) using a SureSelectXT Target Enrichment System Capture NGS strategy library (Agilent Technologies, Santa Clara, CA, USA) before sequencing with MiSeq equipment (Illumina, San Diego, CA, USA). The bioinformatic pipeline included a filtering process excluding intronic, synonymous and single nucleotide polymorphic variants and a selection of driver mutations with potential functional effect (Online Supplementary Methods, Online Supplementary Figure S1). The cancer cell fraction carrying each specific mutation (CCFmut) was calculated as previously described. ${ }^{19}$ As applied to copy number alterations, mutations were classified 
as clonal or subclonal if their cancer cell fractions were $\geq 85 \%$ or $<85 \%$, respectively. ${ }^{19}$ Previously published mutational data from $28 \mathrm{BL}, 203$ PCM and 295 ABC-DLBCL were used for comparisons. ${ }^{24-26}$

\section{Gene expression analysis}

A total of $12 \mathrm{PBL}$ were analyzed using the Nanostring PanCancer Pathways Panel (NanoString, Seattle, WA, USA) to investigate gene expression differences between different subsets of PBL (Online Supplementary Methods, Online Supplementary Table S3).

\section{Statistical analyses}

$\mathrm{R}$ software version 3.6.2 was used for statistical analyses. Differences in the distribution of individual parameters among subsets of patients were analyzed by the Fisher exact test for categorical variables, and the Student $t$-test for continuous variables. Nonparametric Wilcoxon tests were applied when necessary. $P$ values for multiple comparisons were adjusted using the Benjamini-Hochberg correction (false discovery rate). A $P$ value $<0.05$ was considered statistically significant unless otherwise indicated.

\section{Results}

\section{Pathological features and fluorescence in situ hybridization}

Twenty-four patients were male and ten female with a median age of 52 years (range, 11-87 years). HIV infection was confirmed in 14 out of 16 cases with available data $(88 \%)$ and one patient (PBL6) had a post-transplant associated immunodeficiency. Seven patients for whom HIV information was not available were older than 60 years (Table 1). Most cases had an extranodal presentation (84\%), mainly affecting the head and neck region (44\%) and gastrointestinal tract $(30 \%)$. As expected, virtually all cases were negative for B-cell markers, and only two cases showed weak expression of PAX5. Conversely, plasma cell markers such as CD138 and MUM1/IRF4 were positive in $68 \%$ and $100 \%$ of the cases, respectively. CD79a was expressed in $60 \%(18 / 30)$ of the tumors, usually with a focal pattern, and CD56 was positive in 21\% (5/24) (Table 1). EBV (as determined by EBV-encoded small RNA; EBER) was positive in 18 out of $30(60 \%)$ cases whereas human herpes virus-8 was negative in all analyzed cases (Table 1; Figure 1A-H). MYC rearrangements were detected in 26 of the 30 $(87 \%)$ analyzed cases, most of them with IGH as translocation partner (8/9 cases evaluated). Neither BCL2 nor BCL6 translocations were observed (Table 1, Figure 1I, J).

\section{Genomic profiling of plasmablastic lymphomas}

Copy number analysis showed a total of 401 alterations in 33 cases with a median of 12.2 imbalances per case, (range, 3-49) (Online Supplementary Table S4). Specifically, 178 gains, 175 losses, 42 amplifications and six homozygous deletions were detected. The most recurrently gained regions (present in $\geq 20 \%$ ) were $1 \mathrm{q} 21.1-\mathrm{q} 44$, trisomy 7 , 8q23.2-q24.21, 11p13-p11.2, 11q14.2-q25, 12p and 19p13.3-p13.13, whereas recurrent deletions $(\geq 20 \%)$ were identified at 1p33, 1p31.1-p22.3, 13q and 17p13.3-p11.2 (Figure 2A). Furthermore, 46 regions of $\mathrm{CNN}-\mathrm{LOH}$ were detected, with 16q11.2-q24.3 being the most frequently affected region (24\%) (Figure $2 \mathrm{~B})$.

Recurrent amplifications occurred in chromosome 1q, 7
(6 cases each), 11p13-p11.2 and 15q23 regions (2 cases each). Interestingly, the minimal amplified regions of some recurrent amplifications included key genes related to lymphoma biology such as 1q21.3-q23.2 (IL6R, ADAR, MEF2D and CKS1B), 1q32.1-q41 (TRAF5), 11p13-p11.2 (CD44 and TRAF6) and 15q23 (MAP2K5) (Online Supplementary Figure S2). ${ }^{27,28}$ Besides, 25 of the 42 amplifications identified were observed in the context of a chromothripsis-like pattern (Online Supplementary Methods). No recurrent homozygous deletions were found but one case (PBL15) had a focal homozygous deletion including the $C D K N 2 A / B$ tumor suppressor gene.

\section{Mutational landscape of plasmablastic lymphomas}

Twenty-seven PBL cases were analyzed by next-generation sequencing with a mean coverage of $374 x$ (range, 661688x). One hundred and ninety-four mutations were identified (Online Supplementary Table S5). A total of 133 variants $(69 \%)$ were predicted as potential driver mutations with a mean of 4.9 driver mutations per case. The most recurrently mutated genes were STAT3 (37\%), NRAS and TP53 (33\% each), MYC and EP300 (19\% each) and CARD11, SOCS1 and TET2 (11\% each) (Figure 2C; Online Supplementary Figure S3).

All STAT3 mutations except one were nonsynonymous variants located in the SH2 domain (positions 585 to 688). Two different hotspots were found within the SH2 domain including D661Y/N and Y640F (3 cases each), which have been previously described to upregulate STAT3 downstream target genes. ${ }^{29}$ To assess the STAT3 activation status p-STAT3 was studied by immunhistochemistry in six cases (2 mutated and 4 wild-type). RNA expression of genes related to the JAK-STAT pathway (JAK-STAT pathway score), was also analyzed in 12 cases using the NanoString platform (Online Supplementary Methods). p-STAT3 was positive in four cases $(67 \%)$, including the two mutated cases but also two wild-type cases. The four plasmablastic PCM studied were negative for p-STAT3 (Online Supplementary Figure S4, Online Supplementary Table S6). STAT3 mRNA expression was similar in mutated and unmutated cases but it showed a tendency to be higher in EBV-positive than negative tumors (Wilcoxon test, $P=0.07$ ). (Online Supplementary Results, Online Supplementary Figures S4 and S5). Additionally, there were no significant differences in the expression of JAK-STAT pathway-related genes between STAT3-mutated and wild-type cases (Wilcoxon test; $P=0.15$ ), although a tendency to higher expression was observed in EBV-positive cases (Wilcoxon test; $P=0.1$ ) (Online Supplementary Figure S6).

All 12 TP53 mutations were located in the DNA binding domain and three of them were stop-gain mutations (Figure 2D). Bi-allelic inactivation of TP53 was observed in six cases, all negative for EBV expression, in which the 17p13/TP53 locus was also affected by losses or CNNLOH. NRAS mutations mainly affected the known hotspots Q61 (4 cases) and G13 (3 cases). Finally, all but one exonic MYC mutations were located on the transactivation domain, which has been previously demonstrated to induce MYC stability and inhibition of apoptosis (Figure 2D) ${ }^{30}$ Interestingly, multiple mutations (considering $>10$ variants and including intronic and synonymous ones) were found in the five cases with MYC driver mutations and in one additional case with only intronic mutations, all six with concomitant MYC rearrangements. Additionally, a high rate of these mutations involved activated-induced 
Table 1. Pathological and genetic features of 34 cases of plasmablastic lymphoma.

\begin{tabular}{|c|c|c|c|c|c|c|c|c|c|c|c|c|c|c|}
\hline Case & Location & $\begin{array}{l}\text { Age/ } \\
\text { gender }\end{array}$ & HIV & CD79a & CD20 & PAX5 & CD56 & CD138 & $\begin{array}{l}\text { MUM1/ } \\
\text { IRF4 }\end{array}$ & HIV-8 & EBER & $\begin{array}{l}\text { MYC } \\
\text { BAP }\end{array}$ & $\begin{array}{c}\text { BCL2 } \\
\text { BAP }\end{array}$ & $\begin{array}{c}\text { BCL6 } \\
\text { BAP }\end{array}$ \\
\hline PBL1 & Sinus & $38 / \mathrm{M}$ & - & + & - & $\mathrm{NA}$ & NA & + & + & $\mathrm{NA}$ & - & $\mathrm{N}$ & $\mathrm{N}$ & NA \\
\hline PBL2 & Cervical LN & $43 / \mathrm{M}$ & + & + & - & NA & - & - & + & - & + & $\mathrm{R}$ & $\mathrm{N}$ & NA \\
\hline PBL3 & Mesenteric LN & $49 / \mathrm{M}$ & + & + & - & - & - & - & + & - & - & $\mathrm{R}$ & $\mathrm{N}$ & $\mathrm{N}$ \\
\hline PBL4 & Abdominal mass & $58 / \mathrm{F}$ & NA & + & - & - & NA & - & + & - & - & $\mathrm{N}$ & $\mathrm{N}$ & NA \\
\hline PBL5 & Nasal mucosa & $82 / \mathrm{M}$ & NA & - & - & - & + & + & NA & $\mathrm{NA}$ & + & A & A & NA \\
\hline PBL6 & Sigma & $72 / F$ & $-*$ & $+* *$ & - & $+* *$ & - & + & + & $\mathrm{NA}$ & + & $\mathrm{R}$ & $\mathrm{N}$ & NA \\
\hline PBL7 & Submandibular mass & $37 / \mathrm{M}$ & NA & - & - & $\mathrm{NA}$ & - & - & + & - & + & $\mathrm{NA}$ & $\mathrm{NA}$ & NA \\
\hline PBL8 & Skin & $42 / \mathrm{M}$ & + & + & - & + & - & - & + & - & - & $\mathrm{R}$ & $\mathrm{N}$ & $\mathrm{NA}$ \\
\hline PBL9 & NA & $\mathrm{F}$ & NA & NA & NA & NA & NA & NA & + & NA & NA & $\mathrm{N}$ & $\mathrm{N}$ & $\mathrm{N}$ \\
\hline PBL10 & NA & M & NA & NA & NA & NA & $\mathrm{NA}$ & NA & + & NA & NA & $\mathrm{R}$ & $\mathrm{N}$ & $\mathrm{N}$ \\
\hline PBL12 & Oral mucosa & $56 / \mathrm{F}$ & + & - & - & - & - & NA & + & - & - & $\mathrm{R}$ & $\mathrm{N}$ & $\mathrm{N}$ \\
\hline PBL13 & Gastrostomy & $11 / \mathrm{F}$ & + & + & - & - & - & + & + & - & + & $\mathrm{R}$ & $\mathrm{N}$ & $\mathrm{N}$ \\
\hline PBL14 & Oral mucosa & $49 / \mathrm{M}$ & + & NA & - & $\mathrm{NA}$ & - & $\mathrm{NA}$ & + & - & + & $\mathrm{R}$ & NA & $\mathrm{NA}$ \\
\hline PBL15 & Oral mucosa & $48 / \mathrm{M}$ & + & + & - & - & $\mathrm{NA}$ & $\mathrm{NA}$ & + & - & + & $\mathrm{R}$ & $\mathrm{N}$ & $\mathrm{N}$ \\
\hline PBL16 & Perirectal & $47 / \mathrm{M}$ & + & NA & - & - & - & + & + & - & + & $\mathrm{R}$ & $\mathrm{N}$ & $\mathrm{N}$ \\
\hline PBL17 & Small-large bowel & $80 / \mathrm{F}$ & NA & + & - & NA & + & $\mathrm{NA}$ & $\mathrm{NA}$ & - & - & $\mathrm{R}$ & NA & NA \\
\hline PBL18 & Oral mucosa & 49/M & NA & + & - & NA & - & + & NA & - & + & $\mathrm{R}$ & NA & NA \\
\hline PBL19 & Ethmoid mass & $56 / \mathrm{M}$ & NA & - & - & - & NA & + & + & - & - & $\mathrm{R}$ & NA & A \\
\hline PBL20 & Small bowel & $42 / \mathrm{M}$ & + & + & - & - & NA & + & + & - & + & $\mathrm{R}$ & $\mathrm{N}$ & $\mathrm{N}$ \\
\hline PBL21 & Tongue & $67 / \mathrm{M}$ & NA & + & - & - & - & + & $\mathrm{NA}$ & & - & $\mathrm{R}$ & $\mathrm{N}$ & $\mathrm{N}$ \\
\hline PBL22 & Abdominal mass & 63/M & NA & - & - & - & - & - & + & - & + & $\mathrm{R}$ & NA & NA \\
\hline PBL23 & Stomach mass & $68 / \mathrm{F}$ & NA & - & - & NA & - & + & $\mathrm{NA}$ & NA & NA & $\mathrm{R}$ & NA & NA \\
\hline PBL24 & Mediastinal mass & $51 / \mathrm{M}$ & + & + & - & - & + & + & + & - & - & $\mathrm{R}$ & NA & NA \\
\hline PBL25 & Testis & $49 / \mathrm{M}$ & NA & + & - & - & - & + & + & $\mathrm{NA}$ & + & $\mathrm{R}$ & NA & NA \\
\hline PBL26 & Cervical LN & $59 / \mathrm{F}$ & NA & - & - & - & - & + & + & $\mathrm{NA}$ & - & $\mathrm{R}$ & NA & NA \\
\hline PBL27 & Suprapubic area & $87 / F$ & NA & - & - & - & + & + & + & $\mathrm{NA}$ & + & $\mathrm{R}$ & NA & NA \\
\hline PBL28 & Thyroid mass & $57 / F$ & NA & - & - & - & NA & - & + & NA & - & $\mathrm{R}$ & NA & NA \\
\hline PBL29 & Colon & $74 / \mathrm{M}$ & NA & - & - & - & - & - & + & - & - & $\mathrm{R}$ & NA & NA \\
\hline PBL30 & Testis & M & NA & + & - & - & + & + & + & - & NA & $\mathrm{R}$ & NA & NA \\
\hline PBL31 & Maxilla & 27/M & + & - & - & NA & - & + & + & - & + & NA & NA & NA \\
\hline PBL32 & Palate & $36 / \mathrm{M}$ & + & - & $\mathrm{NA}$ & NA & $\mathrm{NA}$ & + & + & - & + & $\mathrm{NA}$ & NA & NA \\
\hline PBL33 & Submaxillary LN & $30 / \mathrm{M}$ & NA & + & - & - & - & - & + & NA & + & $\mathrm{R}$ & NA & NA \\
\hline PBL34 & Retroperitoneal LN & $40 / \mathrm{M}$ & + & + & - & - & NA & + & + & - & + & $\mathrm{R}$ & NA & NA \\
\hline PBL35 & Anal & $39 / \mathrm{M}$ & + & + & - & NA & - & + & + & NA & + & NA & NA & NA \\
\hline
\end{tabular}

*This patient had a post-transplant associated immunodeficiency. ** Weak and focal positivity. LN: lymph node; M: male; F: female; HIV: human immunodeficiency virus; NA: not available N: negative; R: rearranged; A: amplified.

cytidine deaminase (AID)-motifs (corresponding to sequences WA/TW/WRCY/RGYW/WGCW) ${ }^{31}(65 \%$ vs. $39 \%$ expected; $P<0.05)$ suggesting that those mutations fulfill a somatic hypermutation pattern (Online Supplementary Table S7).

We additionally evaluated the occurrence of mutations in genes within predefined pathogenic pathways (Figure 2E; Online Supplementary Table S2). The MAPK pathway was the most frequently mutated pathway (49\%) in our cohort, with there being recurrent mutations in NRAS $(33 \%)$ and additional mutations in KRAS, BRAF and MAP2K1 (2 cases each) and MAPK1 (1 case). In addition MAP2K 5 was located in the minimal amplified region of 15q23 (2 cases). Other recurrently mutated pathways comprised epigenome/chromatin modifier genes (including EP300 and TET2 mutations, among others) (45\%), JAK-STAT and cell cycle (40\% each), and the NFKB pathway (22\%). In detail, JAK-STAT pathway mutations included the activating STAT3 variants located in the SH2 domain and inactivating mutations of the negative regulator SOCS1. NFkB pathway alterations included CARD11 mutations (3 cases), TNFAIP3, NFKB1, NFKBIE, TRAF3, MYD88 (1 case each) and TRAF5 and TRAF6 amplifications in the minimal amplified region of 1q32.1-q41 and 11p13-p11.2 (2 cases each).

\section{Epstein-Barr virus-positive plasmablastic lymphomas are genetically different from negative cases}

Differences in copy numbers and mutational profiling between EBV-positive and -negative PBL were investigated (Figure 3). Of note, EBV-negative PBL had higher mutational load (8.3 vs. 2.9; Wilcoxon test, $P=0.006$ ) and more frequent TP53, CARD 11 and MYC mutations $(P<0.05)$ whereas EBVpositive PBL tended to harbor frequent mutations affecting the JAK-STAT pathway (STAT3 and SOCS1 mutations) ( $57 \%$ vs. $22 \%$; Fisher test, $P<0.2$ ). EBV-negative PBL also had more mutations affecting epigenome/chromatin modi- 
fiers (EP300, TET2, KMT2D, KMT2C, TAF1, ARID1A, HIST1H1D, HIST1H1E), cell cycle (TP53, MYC) and the NFKB pathway (CARD11, NFKBIE, TRAF3, MYD88) $(P<0.05)$ (Figures $2 \mathrm{E}$ and 3; Online Supplementary Table S5). In terms of copy number alterations, EBV-negative PBL had higher levels of genetic complexity (16 vs. 9 alterations per case; Wilcoxon test, $P=0.08$ ) and recurrent $17 \mathrm{p} 13$ alterations (losses and CNN-LOH; Fisher test, $P=0.025$ ) (Figure 3 ). Differential gene expression analysis between EBV-positive $(n=8)$ and EBV-negative $(n=4)$ PBL identified seven differentially expressed genes ( $t$-test, false discovery rate [FDR] $<0.2$ and fold change $> \pm 1$ ) (Online Supplementary Table S3). Gene ontology analysis of those genes showed that EBV-negative cases had lower expression of genes related to hypoxia and p53 in the cardiovascular system (FDR=0.006) and p53 signaling pathways ( $F D R=0.13$ ).

\section{Clonal evolution in plasmablastic lymphomas}

To analyze the hierarchy of genetic events in PBL, the cancer cell fraction was determined for 357 alterations (including 250 copy number alterations and 107 mutations) from $24 \mathrm{PBL}$ cases, of which $31 \%$ were clonal (cancer cell fraction $>85 \%$ ) (Online Supplementary Tables S4 and S5). The majority of alterations showed a wide spectrum of cancer cell fractions, except for TP53 mutations, 17 losses and 13q deletions which were mainly clonal (Shapiro test; $P<0.05$ ) (Online Supplementary Figure S7). Interestingly, clonal and subclonal mutations targeting recurrently mutated genes (STAT3, NRAS, TP53 and MYC) affected the same protein domains, suggesting that those subclonal driver mutations confer similar advantage to the cell (Online Supplementary Figure S8).

\section{Comparison with overlapping lymphoma entities}

Copy number data of 35 cases of $\mathrm{BL}^{20}$ were re-evaluated for comparison with the current $\mathrm{PBL}$ series (Online Supplementary Figure S9). PBL had higher levels of genomic complexity than BL (12.2 vs. 5.97 alterations/case; Wilcoxon test, $P<0.01)$ with specific gains of $1 \mathrm{q} 32.2-\mathrm{q} 44,7 \mathrm{p}, 8 \mathrm{q} 23.3$, 11p13-p11.2, 11q23.3-q25, 12p13.32-p13.2, and 19p13.3p13.12. We also compared the mutational landscape of our series with that of $28 \mathrm{BL} .{ }^{24} \mathrm{PBL}$ displayed specific NRAS, STAT3 and EP300 mutations, fewer MYC mutations, and lack of aberrations in genes reported to be specifically associated with $\mathrm{BL}$ pathogenesis such as ID3, SMARCA4 and TCF3 (Fisher test; $P<0.05$ ) (Figure $4 \mathrm{~A}$ ).
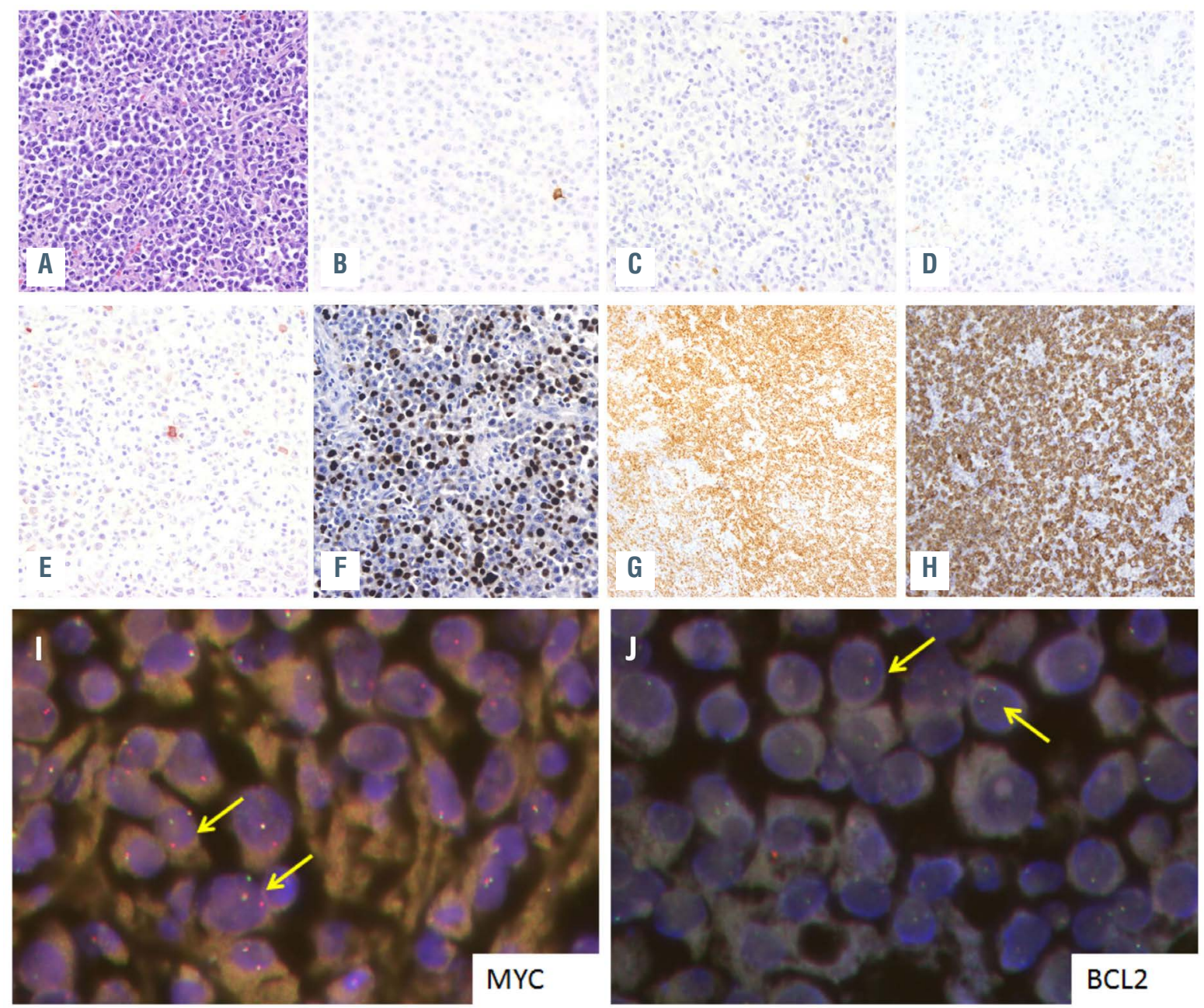

Figure 1. Plasmablastic lymphoma morphology and immunophenotype. Morphology and immunophenotype of case PBL6. (A) Plasmablastic lymphoma (PBL) with plasmacytic differentiation (hematoxilin-eosin, original magnification x400). The tumor cells were negative for (B) CD20, (C) showed weak and focal expression for PAX5, (D) were negative for CD56 and (E) also presented weak and focal positivity for CD79a. The case was positive for (F) EBER, (G) MUM1/IRF4 and (H) CD138 (magnification x400). (I, J) Fluorescence in situ hybridization (FISH) analysis identified a MYC rearrangement (I) but absence of BCL2 rearrangements (J). Yellow arrows indicate FISH signal constellations. 
The copy number profile of 49 cases of ABC-DLBCL was compared with that of $\mathrm{PBL}$ (Online Supplementary Figure S10). ${ }^{21}$ PBL displayed lower levels of genetic complexity (12.2 vs. 22.1 alterations/case; Wilcoxon test, $P<0.01$ ), more frequently carried gains of 1q32.2-qter but lacked gains of $3 q, 18 q$ and $19 q 13.43$ compared to ABC-DLBCL. PBL also lacked recurrent 9p21.3 alterations typically seen in $\mathrm{ABC}$ DLBCL. In comparison with ABC-DLBCL, ${ }^{25} \mathrm{PBL}$ had more frequent STAT3 and NRAS mutations, a lower incidence of $K M T 2 D$ mutations and virtual absence of mutations affecting the NFkB pathway (Figure 4B).

Compared to 41 cases of PCM, ${ }^{22,23}$ PBL had similar levels of genetic complexity in terms of the copy number profile (12.6 vs. 13 alterations/case; Wilcoxon test, $P=0.5$ ) (Online Supplementary Figure S11). PBL resembled PCM for the presence of 1q gains and trisomy 7 but carried significantly more gains of $12 \mathrm{p}$. Otherwise, PBL lacked trisomies typically seen in hyperdiploid PCM (chromosomes 3, 5, 9, 11, 15, 19 and 21). Regarding the mutational landscape, PBL resembled $\mathrm{PCM}^{26}$ as both harbor recurrent mutations targeting MAPK pathway genes (NRAS, KRAS and BRAF) (Figure 4C). Nonetheless, PBL had more TP53, STAT3, and MYC mutations, among others (Fisher test, $P<0.05$ ).

\section{Discussion}

In this study we performed a large-scale, high-resolution analysis of genomic alterations in 34 cases of PBL. MYC rearrangement was present in $87 \%$ of the cases, a higher incidence than previously reported (50\%), ${ }^{2,6}$ These MYC rearrangements may intensify $M Y C$ activity in cell proliferation, cell growth, DNA replication, cell metabolism, and cell survival, as described in other lymphomas, such as BL. ${ }^{32}$ Multiple $M Y C$ mutations were identified in six cases with concomitant $M Y C$ rearrangement (5 cases including exonic mutations and 1 case with only intronic mutations). These mutations were observed $2.5 \mathrm{~kb}$ after a transcript start site (including exon1-intron1-exon2) involving AID-motifs, suggestive of an aberrant somatic hypermutation pattern. . $^{31,33}$

The copy number landscape of our PBL series was characterized by high genetic complexity (12.2 alterations/case) and recurrent 1q21.1-q44, trisomy 7, 8q23.2-q24.21, 11p13$\mathrm{p} 11.2,11 \mathrm{q} 14.2-\mathrm{q} 25,12 \mathrm{p}$ and 19p13.3-p13.13 gains and $1 \mathrm{p} 33,1 \mathrm{p} 31.1-\mathrm{p} 22.3,13 \mathrm{q}$ and $17 \mathrm{p} 13.3-\mathrm{p} 11.2$ losses. Some of these alterations had been previously identified in PBL.,10 However, our analysis identified novel regions of alteration such as losses of $13 q$ and 17p13.3-p11.2 or 16q11.2-q24.3

A

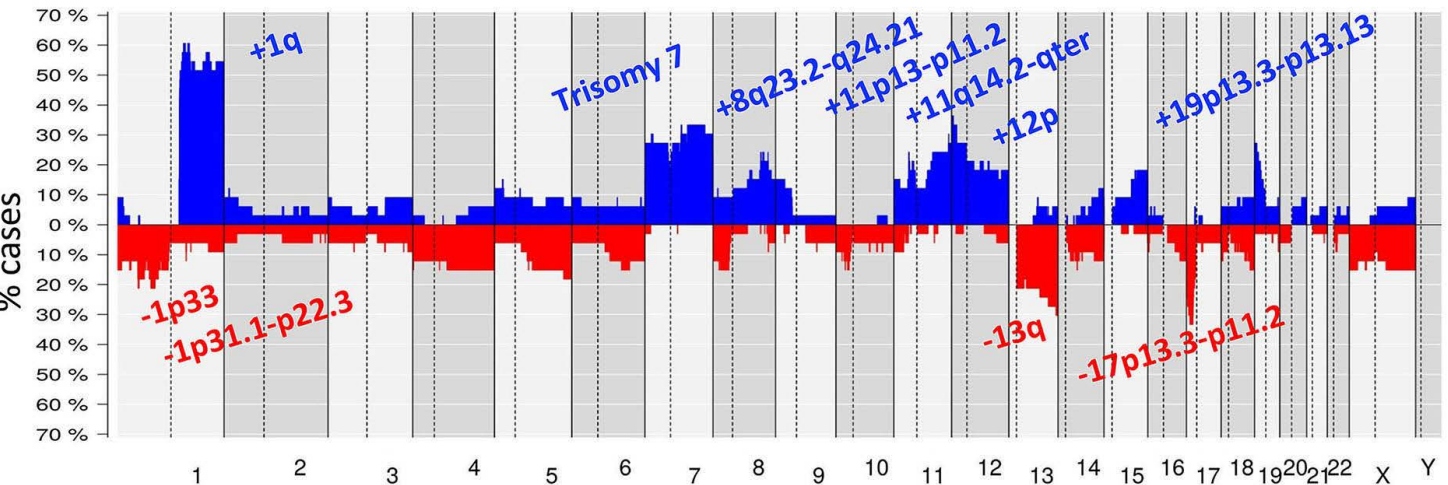

B

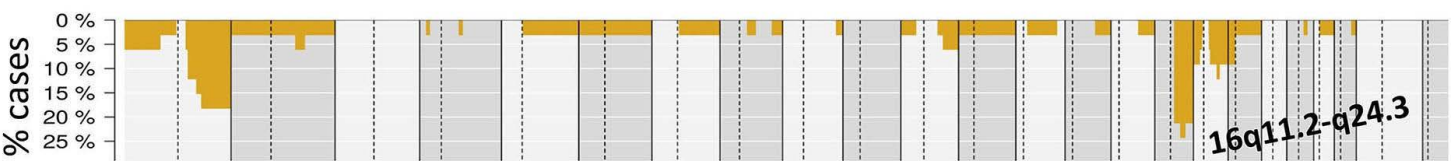

C

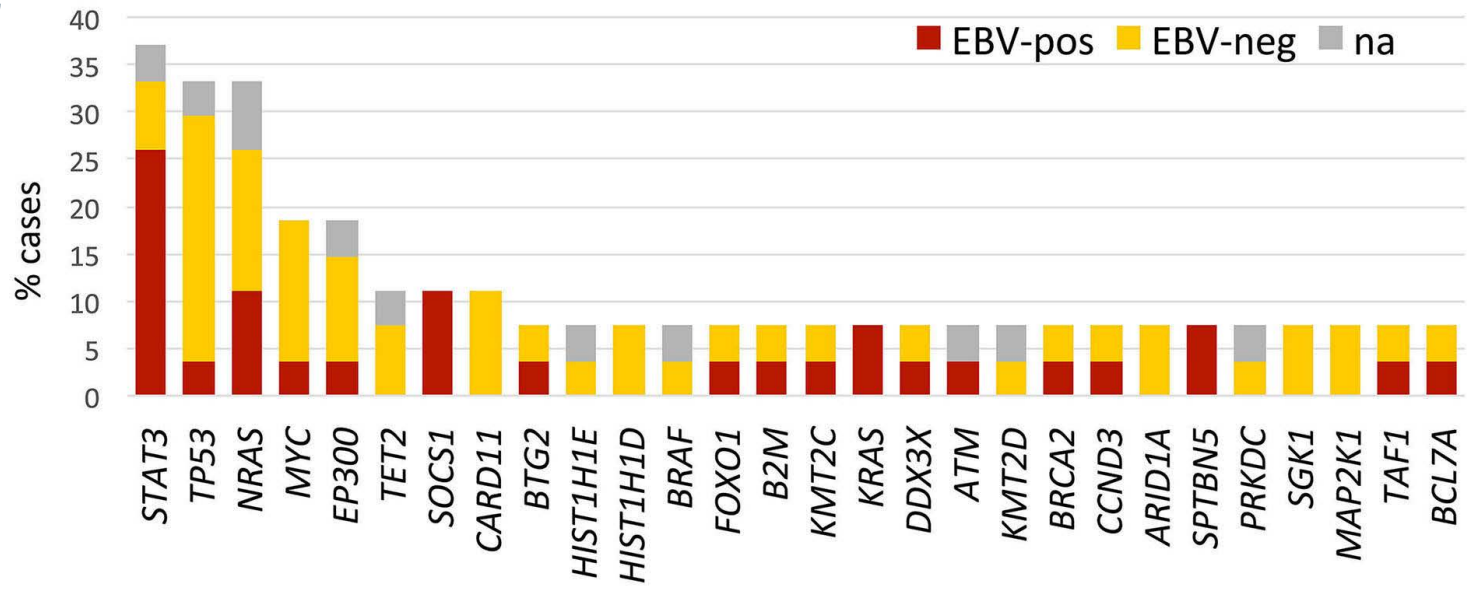

Figure 2. Continued on the following page. 
D STAT3

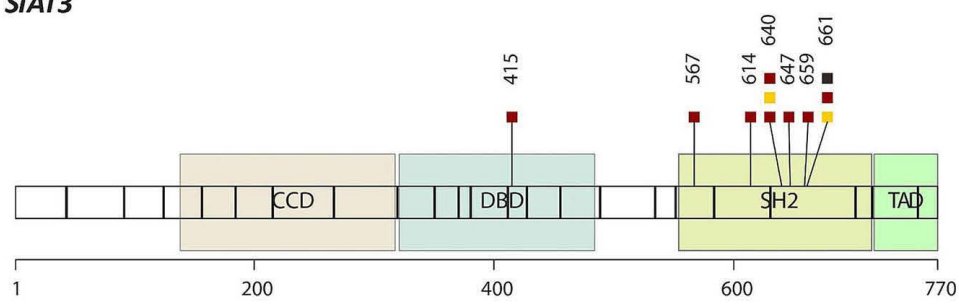

\section{Mutation type \\ - Truncating \\ Missense \\ EBV-pos \\ EBV-neg \\ na}

TP53

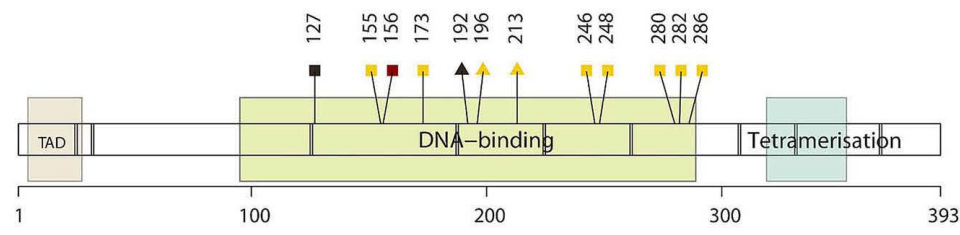

NRAS

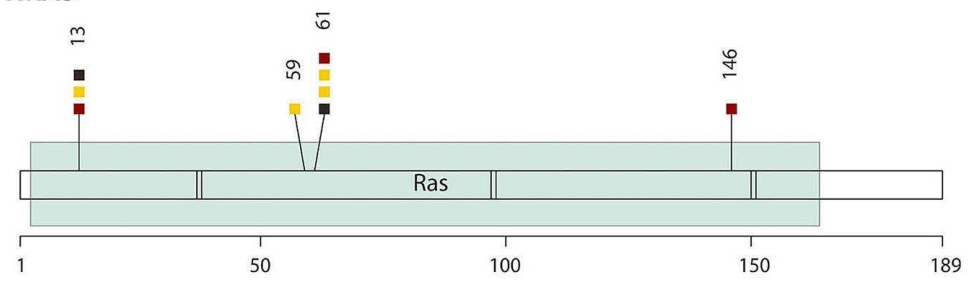

MYC
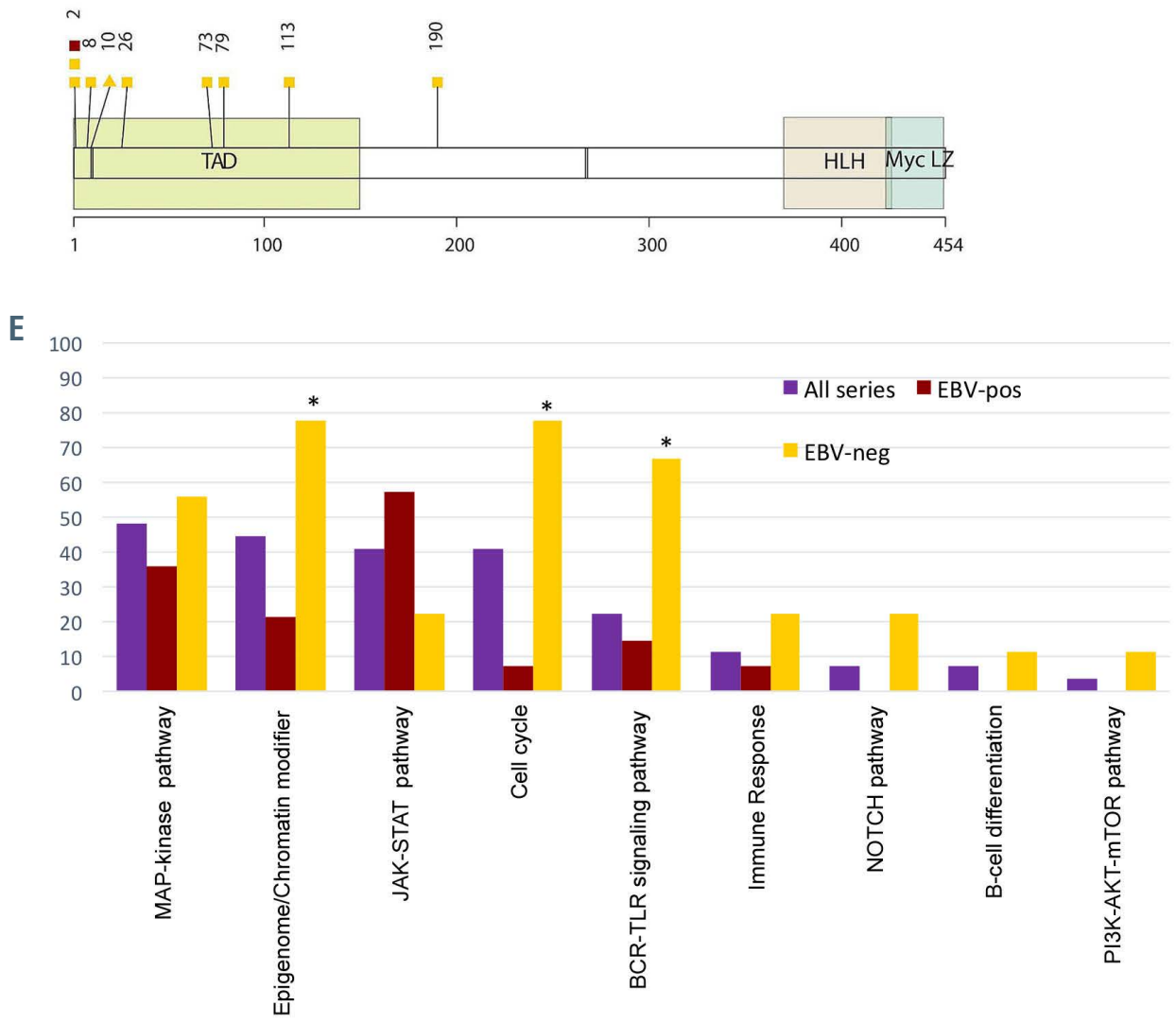

Figure 2. Genetic alterations of plasmablastic lymphoma. (A) Global copy number and (B) copy number neutral loss of heterozygosity (CNN-LOH) profile of 33 cases of plasmablastic lymphoma (PBL). The x-axis indicates chromosomes from 1 to $Y$ and $p$ to $q$. The $y$-axis indicates the frequency of the genomic aberration among the cases analyzed. Gains are depicted in blue, losses are depicted in red and CNN-LOH are depicted in yellow. Recurrent copy number and CNN-LOH regions ( $>20 \%$ of cases) are indicated. (C) Bar plot showing genes mutated in more than $5 \%$ of 27 cases of PBL. The color of the bar indicates the Epstein-Barr virus (EBV) infection status. (D) A diagram of the relative positions of driver mutations is shown for STAT3, TP53, NRAS and MYC genes. The x-axes indicate amino acid positions. CCD: coiled coil domain; DBD: DNA-binding domain; TAD: transcription activation domain; HLH: helix-loop-helix; LZ: leucine zipper. (E) Recurrent mutated pathways in 27 PBL. The bar graph shows the total number of mutated cases for each pathway. Asterisks represent significant mutated pathways in EBV-negative ( $n=9)$ versus positive ( $n=14)$ PBL 
CNN-LOH. Our cases showed recurrent regions of amplification with some of them in the context of chromothripsislike patterns. Amplifications of 1q21 had already been described as an important prognostic marker in $\mathrm{PCM} .{ }^{34} \mathrm{We}$ also identified IL6R, ADAR and CKS1B genes included in the 1q21.3-q23.2 amplified region. ${ }^{27,28}$ These genes have been identified to drive disease aggressiveness in 1q21amplified PCM cases, and consequently, could be considered possible targets of the 1q21 amplification..$^{27,28}$ In detail, 1q21 amplification and overexpression of $C K S 1 B$ have been described to confer poor prognosis in PCM, as a result of enhanced degradation of p27/Kip1. ${ }^{28}$ Besides, IL6R and $A D A R$ genes cooperate, inducing hyperactivation of the JAK-STAT pathway, leading to the transcription of pro-survival and anti-apoptotic genes in $\mathrm{PCM}^{27}$ Of note, the copy number profile identified in $\mathrm{PBL}$ differed from that in other lymphoma entities such as BL, ABC-DLBCL and PCM. PBL were genetically more complex than $\mathrm{BL}$, and lacked common aberrations of ABC-DLBCL such as 9p21.3 losses and $18 q$ gains or typical trisomies of the hyperdiploid profile found in PCM. On the other hand, PBL had specific alterations including gains of $12 \mathrm{p}$ (including $K R A S$ ) and 16q11.2q24.3 CNN-LOH.

Regarding the mutational profile of $\mathrm{PBL}$, the most frequently mutated genes were STAT3, NRAS and TP53, followed by MYC, EP300, CARD11, SOCS1 and TET2. These mutations mainly affect the MAPK pathway, epigenome/chromatin modifier genes, the JAK-STAT pathway and cell cycle genes. Altough some of these results have already been described (Online Supplementary Figure
S12),, 10 we also demonstrated a previously undetected association between clonal TP53 alterations and EBV negativity. Interestingly, several of those genes could be targets for novel therapies (Online Supplementary Table S8). The identification of recurrent STAT3 and NRAS mutations is in line with recent results in HIV-positive PBL in South Africa. ${ }^{10}$ Moreover, Garcia-Reyero et al. also found recurrent missense PRDM1 mutations, ${ }^{9}$ which we were not able to identify in our cases. Several of those described PRDM1 mutations were predicted in the study as neutral, in contrast to the truncating PRDM1 mutations associated with $\mathrm{ABC}$ DLBCL. ${ }^{35}$

In our study we identifed recurrently mutated pathways that have an important role in the pathogenesis of PBL. In this sense, the MAPK pathway was the most frequently mutated pathway, with mutations in NRAS, KRAS, BRAF and $M A P 2 K 1$ being found in $49 \%$ of the cases. This finding is similar to the recent observation in South-African patients and highlights its relevance in PBL. ${ }^{10} K R A S$ and NRAS mutations were mainly located in the hotspot amino acid positions 13 and 61, previously described to impair intrinsic GTPase activity, leading to constitutive activation of the MAPK pathway. ${ }^{36}$ Two $B R A F$ mutations affecting the G469V/A position and located on the p-loop of the kinase domain were also recognized. These mutations have been demonstrated in lung cancer to induce a higher kinase activity compared to non-mutated $B R A F{ }^{37}$ These MAPK pathway mutations were also frequently found in PCM (46$59 \%$ of cases), leading to MEK/ERK activation and resulting in increased proliferation, growth and survival. ${ }^{26,38}$

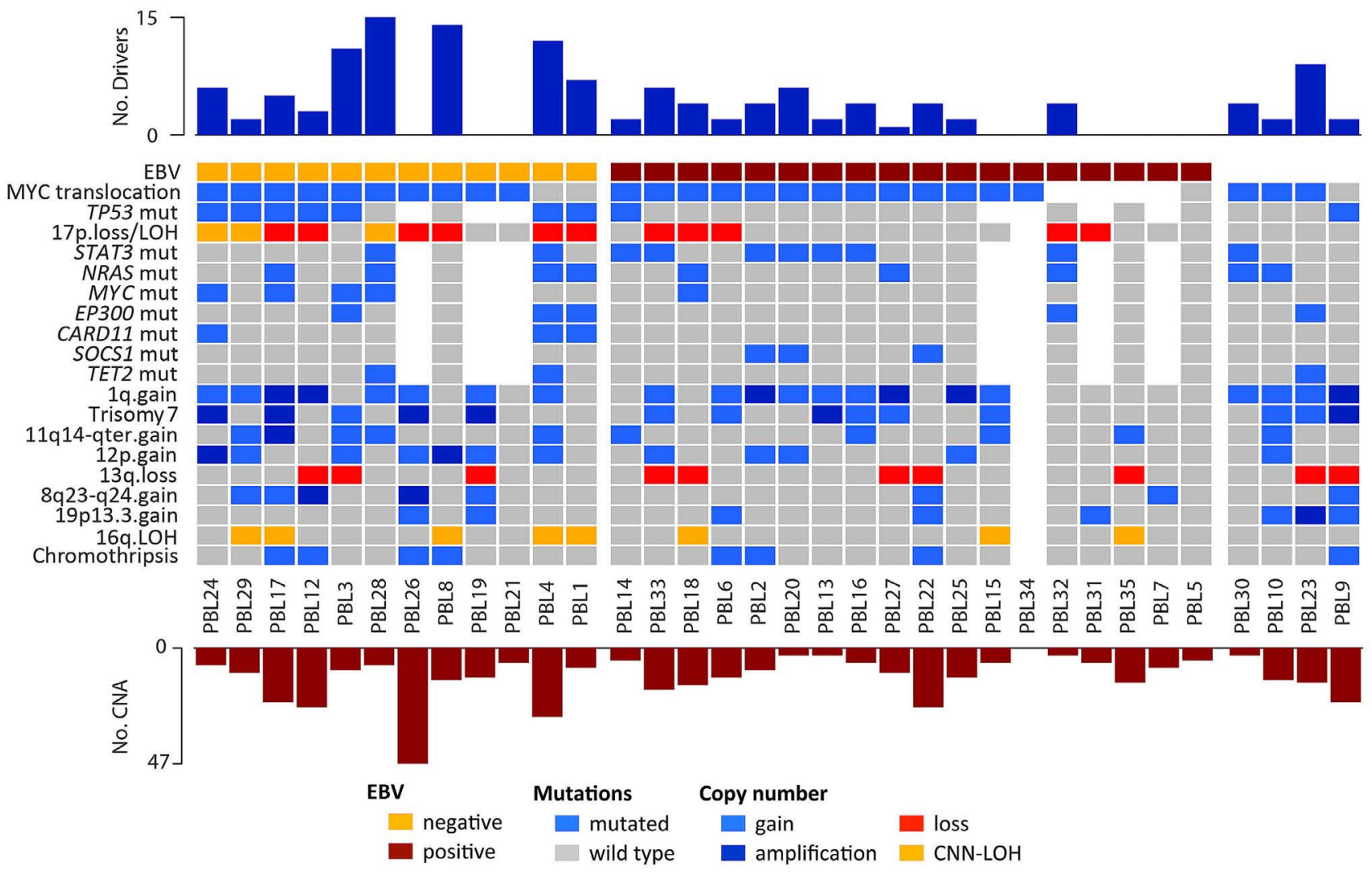

Figure 3. Overview of recurrent alterations in plasmablastic lymphomas. Different rows represent recurrent mutations ( $>10 \%)$ and copy number alterations ( $>25 \%$ ). The upper bar plot indicates the number of driver mutations per case whereas the lower bar plot indicates the number of copy number alterations per case. EBV: Epstein-Barr virus; LOH: loss of heterozygosity, CNN-LOH: copy number neutral loss of heterozygosity; CNA: copy number alteration. 
A $\quad B L(n=28)$

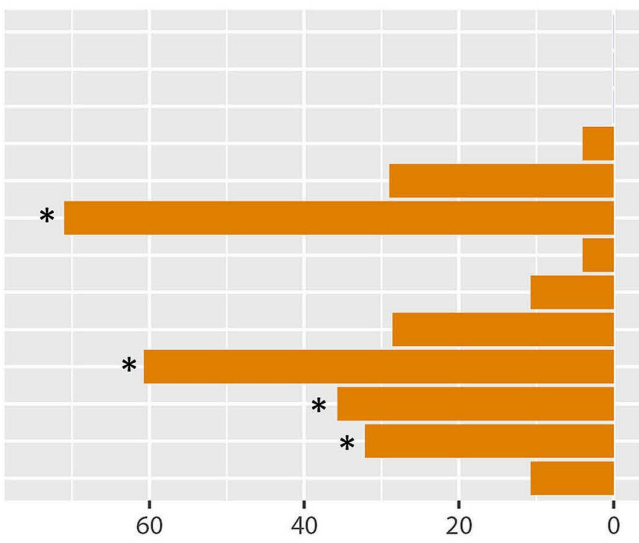

B

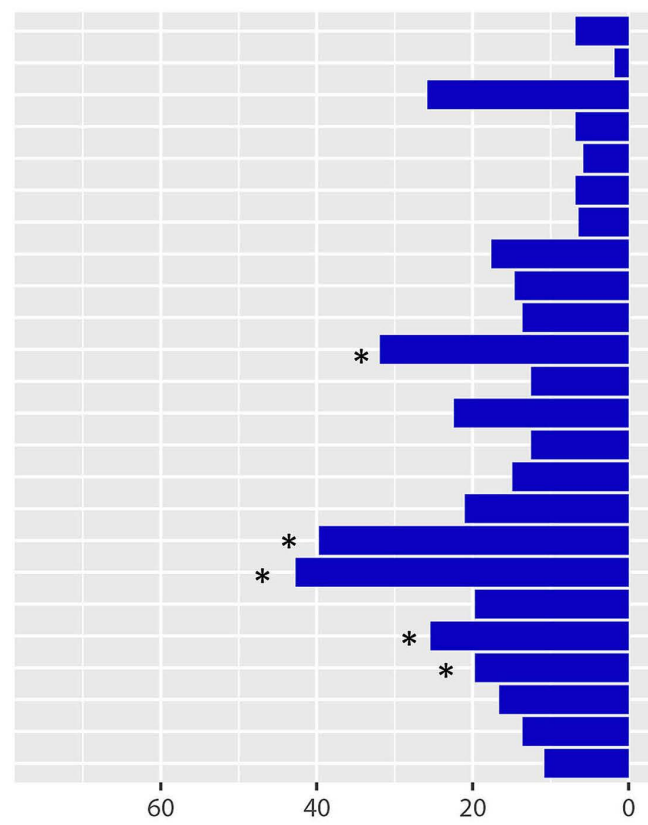

C

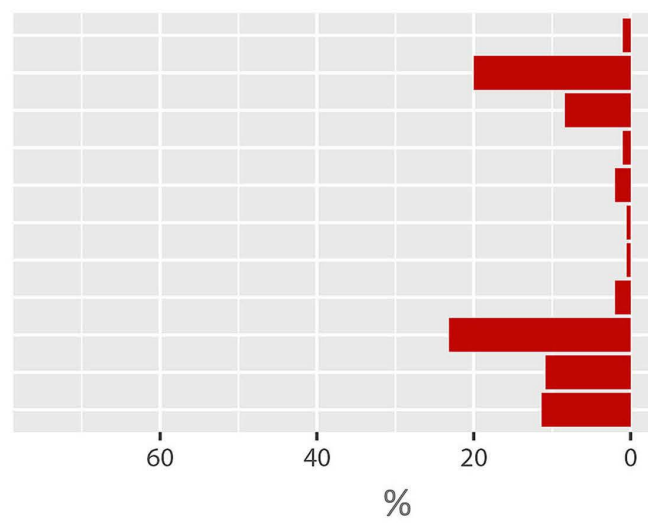

60

40

20

$\operatorname{PCM}(n=203)$
NRAS

EP300

SOCS1

STAT3

TP53

MYC

TET2

CARD11

DDX3X

ID3

SMARCA4

TCF3

GNA13

jo
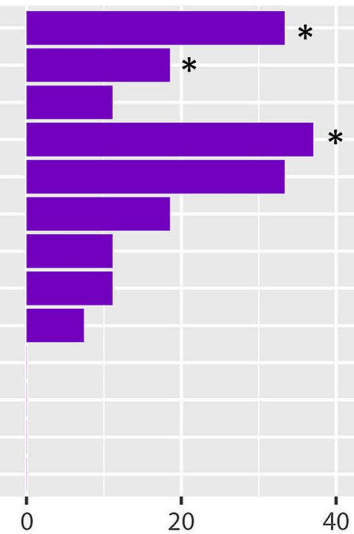

$40 \quad 60$

$\operatorname{PBL}(n=27)$

STAT3

NRAS

TP53

EP300

MYC

SOCS1

TET2

CARD11

HIST1H1E

CCND3

KMT2D

B2M

BTG2

CREBBP

TNFAIP3

BTG1

MYD88

PIM1

PRDM1

CD79B

TBLIXR1

ETV6

IRF4

BCL6

STAT3

NRAS

TP53

EP300

MYC

SOCS1

TET2

CARD11

KRAS

DIS3

FAM46C

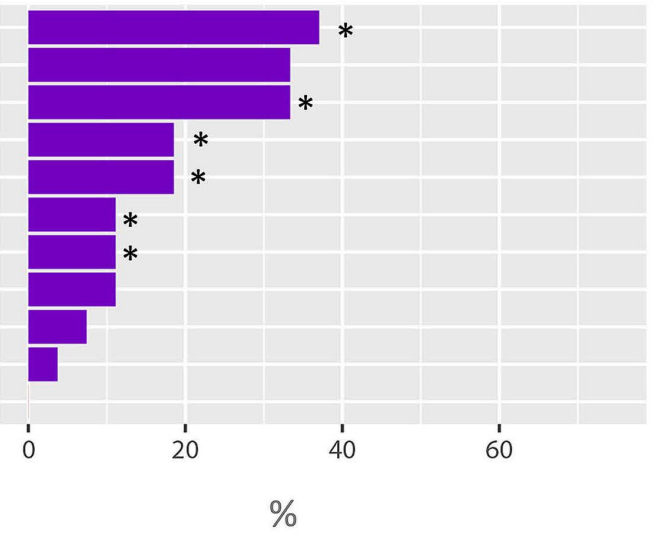

Figure 4. Comparison between mutations in plasmablastic lymphomas and other related lymphoid neoplasms. Percentage of mutated cases in 27 cases of plas mablastic lymphoma (PBL) compared to (A) 28 cases of Burkitt lymphoma (BL) ${ }^{24}$ (B) 295 cases of activated B-cell like diffuse large B-cell lymphoma (ABC-DLBCL) and (C) 203 cases of plasma cell myeloma (PCM) ${ }^{26}$ including the most frequently mutated genes interrogated in both series (>10\%). Asteriskes indicate differentially mutated genes between groups (false discovery rate $<0.05$ ). 
The JAK-STAT pathway was also mutated in $40 \%$ of our cases. We found recurrent activating STAT3 variants located in the $\mathrm{SH} 2$ domain, in addition to inactivating mutations in SOCS1, a negative regulator of the JAK-STAT pathway. Activating STAT3 mutations and expression of the activated protein are frequently seen in T-cell and NK-cell malignancies but are rare in B-cell lymphomas, being previously described only in high-grade B-cell lymphoma, a subset of $\mathrm{CD} 0^{+} \mathrm{DLBCL}$ and $\mathrm{ALK}^{+}$large B-cell lymphoma, which also has a plasmablastic phenotype. ${ }^{29,39,40}$ Moreover, these STAT3 mutations have been suggested to confer hydrophobicity, facilitating the activation of STAT3 through Y705 phosphorylation and the consequent upregulation of STAT3 downstream target genes. ${ }^{29}$

Immunohistochemical staining for p-STAT3 demonstrated positivity in $67 \%$ of the cases independently of the STAT3 mutational status. The same results were obtained by Liu et al. In addition, no differences in the expression of JAK-STAT pathways were observed in STAT3-mutated and wild-type tumors. Although the number of cases is limited, these results suggest that PBL may have alternative mechanisms of STAT pathway activation. ${ }^{10}$ Interestingly, plasmablastic PCM were negative for $\mathrm{p}$-STAT3. The potential diagnostic value of this difference deserves further confirmation.

Independently of these activating mutations, the JAKSTAT pathway is also deregulated in PCM and ABCDLBCL, promoting cell survival and proliferation. . $^{41,42}$ In addition, the interaction of $I L 6$ with its receptor IL6R has been described to induce STAT3 activation in PCM cell lines. ${ }^{43}$ Interestingly, a newly established PBL cell line has been demonstrated to be dependent on IL6 for proliferation and survival. ${ }^{44}$ All these findings suggest the importance of IL6/JAK/STAT3 signaling in the pathogenesis of PBL disease.

On the other hand, in addition to $M Y C$ rearrangements, genes governing the cell cycle were also affected in PBL by other mechanisms including bi-allelic inactivation of important regulator genes such as TP53 and CDKN2A. Of note, these TP53 alterations, including mutations and deletions, were restricted to EBV-negative $\mathrm{PBL}$, without other associated clinical, morphological or molecular features. The low frequencies of TP53 mutations identified in previous studies is probably due to the small number of EBV-negative cases in those series (Online Supplementary Figure S12). 8,10

Interestingly, the mutational landscape of PBL differed from that of $\mathrm{BL}$ since it lacked variants affecting genes related to $\mathrm{BL}$ pathogenesis such as ID3, SMARCA4 and TCF3. Moreover, compared with ABC-DLBCL, PBL lacked typical MYD88-L265P and CD79B mutations, affecting NFkB pathway. Finally, PBL resembles PCM for the presence of mutations affecting the MAPK pathway. ${ }^{26}$ Mutations in this pathway were detected as clonal or subclonal in different cases. In contrast, TP53 alterations and NRAS mutations were frequently clonal, suggesting that they are early events in PBL in addition to MYC rearrangements.

As previously observed in other lymphoma subtypes, our results suggest that EBV-positivity defines a specific PBL phenotype with particular molecular properties such as lower levels of genetic complexity, and distinct pathogenic mechanisms. ${ }^{9,45-48}$ Specifically, EBV-positive PBL showed more frequent STAT3 mutations whereas inactivating TP53 alterations (mutations, deletions and CNN-LOH) were sig- nificantly enriched in EBV-negative tumors, which have lower expression of p53 signaling pathway-related genes. In BL, EBV positivity has also been associated with fewer driver mutations, especially among apoptosis-related genes such as TP53. ${ }^{45}$ Additionally, similar to PBL, EBV-positive DLBCL had relatively fewer genomic alterations than EBVnegative DLBCL, whereas EBV-negative cases had more $17 \mathrm{p}$ deletions. ${ }^{48}$ This suggests two different mechanisms to avoid apoptosis in which TP53 depletion substitutes for the anti-apoptotic effect that EBV infection exerts in the cell. In addition, EBV-negative PBL have a higher frequency of mutations affecting epigenome/chromatin modifiers and NFKB signaling pathways. In ABC-DLBCL, genetic alterations of BCR-TLR pathways lead to high NFKB activity which induces production of IL- 6 and IL-10.49,50 These observations suggest that an autocrine action of IL- 6 could also occur in EBV-negative PBL, activating the JAK-STAT pathway as an alternative mechanism to STAT3 mutations present in EBV-positive cases.

In summary, we used an integrative approach of FISH copy number and next-generation sequencing mutational analyses in a large series of PBL. Our results revealed a specific PBL genetic landscape which, differing from that of other related lymphoma entities, is characterized by recurrent alterations in the MAPK and JAK-STAT pathways in addition to previously known $M Y C$ rearrangements. Moreover, we identified a distinct mutation profile for EBVpositive and EBV-negative cases, a finding observed in other forms of aggressive B-cell lymphoma. The detection of recurrently altered MAPK and JAK-STAT pathways in PBL opens new perspectives in the biology of this disease, identifying possible new targets for therapy.

\section{Disclosures}

No conflicts of interest to disclose.

\section{Contributions}

$J E R-Z$ performed research, analyzed data and wrote the manuscript; $B G-F$. performed morphological diagnoses, analyzed data and wrote the manuscript; GC, FN, AM, HH, GW, DWS, AV and $A E$ performed research and analyzed data; $A N, S P, J Y S, K F$, $R D G, W C C, A L F, R M B, E B S, L M S, A R, L M R, G O$ and ESJ reviewed and interpreted pathological and/or clinical data; IS performed research, analyzed data, designed research and wrote the manuscript; EC performed morphological analyses, designed research and wrote the manuscript. All authors approved the final version of the manuscript.

\section{Acknowledgments}

We thank Noelia Garcia, Miriam Prieto, Silvia Martín, and Helena Suarez for their excellent technical assistance. We are indebted to the IDIBAPS Genomics Core Facility and to the HCBIDIBAPS Biobank-Tumor Bank.

\section{Funding}

This work was supported by Spanish Ministerio de Economia y Competitividad, grant RTI2018-094274-B-I00 (to EC), National Institutes of Health "Molecular Diagnosis, Prognosis, and Therapeutic Targets in Mantle Cell Lymphoma" (grant 1P01CA229100), and the European Regional Development Fund "Una manera de fer Europa". Generalitat de Catalunya Suport Grups de Recerca (2017-SGR-1107 to IS and 2017$S G R-1142$ to EC), JER-Z was supported by a fellowship from Generalitat de Catalunya AGAUR FI-DGR 2017 (2017 FI_B01004). EC is an Academia Researcher of the "Institució 
Catalana de Recerca i Estudis Avançats" (ICREA) and CERCA Programme of the Generalitat de Catalunya. This work was developed at the Centro Esther Koplowitz, Barcelona, Spain. The group is supported by Accio instrumental d'incorporacio de cientifics $i$ tecnolegs PERIS 2016 (SLT002/16/00336) from the Generalitat de Catalunya.

\section{Data-sharing statement}

The copy-number data reported in this article have been deposited in the Gene Expression Omnibus database under accession number GSE155055. Sequencing data have been deposited in the European Nucleotide Archive (ENA, accession number ERP123243).

\section{References}

1. Swerdlow SH, Campo E, Harris NL, et al. (Eds) WHO Classification of Tumours of Haematopoietic and Lymphoid Tissues (Revised 4th edition). IARC Lyon 2017.

2. Montes-Moreno S, Gonzalez-Medina A-R, Rodriguez-Pinilla S-M, et al. Aggressive large B-cell lymphoma with plasma cell differentiation: immunohistochemical characterization of plasmablastic lymphoma and diffuse large B-cell lymphoma with partial plasmablastic phenotype. Haematologica. 2010;95(8):1342-1349.

3. Morscio J, Dierickx D, Nijs J, et al. Clinicopathologic comparison of plasmablastic lymphoma in HIV-positive, immunocompetent, and posttransplant patients: single-center series of 25 cases and meta-analysis of 277 reported cases. Am J Surg Pathol. 2014;38(7):875-886.

4. Castillo JJ, Bibas M, Miranda RN. The biology and treatment of plasmablastic lymphoma. Blood. 2015;125(15):2323-2330.

5. Dong HY, Scadden DT, de Leval L, Tang Z, Isaacson PG, Harris NL. Plasmablastic lymphoma in HIV-positive patients: an aggressive Epstein-Barr virus-associated extramedullary plasmacytic neoplasm. Am J Surg Pathol. 2005;29(12):1633-1641.

6. Valera A, Balague O, Colomo L, et al. IG/MYC rearrangements are the main cytogenetic alteration in plasmablastic lymphomas. Am J Surg Pathol. 2010;34(11): 1686-1694.

7. Taddesse-Heath L, Meloni-Ehrig A, Scheerle J, Kelly JC, Jaffe ES. Plasmablastic lymphoma with MYC translocation: evidence for a common pathway in the generation of plasmablastic features. Mod Pathol. 2010;23(7):991-999.

8. Chang C-C, Zhou X, Taylor JJ, et al. Genomic profiling of plasmablastic lymphoma using array comparative genomic hybridization $(\mathrm{aCGH})$ : revealing significant overlapping genomic lesions with diffuse large B-cell lymphoma. J Hematol Oncol. 2009;2:247

9. Garcia-Reyero J, Martinez Magunacelaya N, Gonzalez de Villambrosia S, et al. Genetic lesions in MYC and STAT3 drive oncogenic transcription factor overexpression in plasmablastic lymphoma. Haematologica. 2021;106(4):1120-1128

10. Liu Z, Filip I, Gomez K, et al. Genomic characterization of HIV-associated plasmablastic lymphoma identifies pervasive mutations in the JAK-STAT pathway. Blood Cancer Discov. 2020;1(1):112-125.

11. Chapman J, Gentles AJ, Sujoy V, et al. Gene expression analysis of plasmablastic lymphoma identifies downregulation of B-cell receptor signaling and additional unique transcriptional programs. Leukemia. 2015;29(11):2270-2273.

12. Hans CP, Weisenburger DD, Greiner TC, et al. Confirmation of the molecular classification of diffuse large B-cell lymphoma by immunohistochemistry using a tissue microarray. Blood. 2004;103(1):275-282.
13. Bea S, Zettl A, Wright G, et al. Diffuse large B-cell lymphoma subgroups have distinct genetic profiles that influence tumor biology and improve gene-expression-based survival prediction. Blood. 2005;106(9):3183-3190.

14. Glitza IC, Lu G, Shah R, et al. Chromosome 8q24.1/c-MYC abnormality: a marker for high-risk myeloma. Leuk Lymphoma. 2015;56(3):602-607.

15. Tchernonog E, Faurie P, Coppo P, et al. Clinical characteristics and prognostic factors of plasmablastic lymphoma patients: analysis of 135 patients from the LYSA group. Ann Oncol. 2017;28(4):843-848.

16. Castillo JJ, Winer ES, Stachurski D, et al. Prognostic factors in chemotherapy-treated patients with HIV-associated plasmablastic lymphoma. Oncologist. 2010;15(3):293-299.

17. Guerrero-Garcia TA, Mogollon RJ, Castillo JJ. Bortezomib in plasmablastic lymphoma: A glimpse of hope for a hard-to-treat disease. Leuk Res. 2017;62:12-16.

18. Nadeu F, Clot G, Delgado J, et al. Clinical impact of the subclonal architecture and mutational complexity in chronic lymphocytic leukemia. Leukemia. 2018;32(3):645653.

19. Landau DA, Tausch E, Taylor-Weiner AN, et al. Mutations driving CLL and their evolution in progression and relapse. Nature. 2015;526(7574):525-530.

20. Scholtysik R, Kreuz M, Klapper W, et al. Detection of genomic aberrations in molecularly defined Burkitt's lymphoma by arraybased, high resolution, single nucleotide polymorphism analysis. Haematologica. 2010;95(12):2047-2055

21. Karube K, Enjuanes A, Dlouhy I, et al. Integrating genomic alterations in diffuse large B-cell lymphoma identifies new relevant pathways and potential therapeutic targets. Leukemia. 2018;32(3):675-684.

22. Lopez-Corral L, Sarasquete ME, Bea S, et al. SNP-based mapping arrays reveal high genomic complexity in monoclonal gammopathies, from MGUS to myeloma status. Leukemia. 2012;26(12):2521-2529.

23. Paiva B, Corchete LA, Vidriales M-B, et al. Phenotypic and genomic analysis of multiple myeloma minimal residual disease tumor cells: a new model to understand chemoresistance. Blood. 2016;127(15):18961906.

24. Schmitz R, Young RM, Ceribelli M, et al. Burkitt lymphoma pathogenesis and therapeutic targets from structural and functional genomics. Nature. 2012;490(7418):116-120.

25. Schmitz R, Wright GW, Huang DW, et al. Genetics and pathogenesis of diffuse large Bcell lymphoma. N Engl J Med. 2018;378 (15):1396-1407

26. Lohr JG, Stojanov P, Carter SL, et al. Widespread genetic heterogeneity in multiple myeloma: implications for targeted therapy. Cancer Cell. 2014;25(1):91-101.

27. Teoh PJ, Chung T-H, Chng PYZ, Toh SHM, Chng WJ. IL6R-STAT3-ADAR1 (P150) interplay promotes oncogenicity in multiple myeloma with 1q21 amplification. Haematologica. 2020;105(5):1391-1404.
28. Shaughnessy J. Amplification and overexpression of CKS1B at chromosome band 1q21 is associated with reduced levels of p27Kip1 and an aggressive clinical course in multiple myeloma. Hematology. 2005;10 (Suppl 1):117-126.

29. Koskela HLM, Eldfors S, Ellonen P, et al. Somatic STAT3 mutations in large granular lymphocytic leukemia. N Engl J Med. 2012;366(20):1905-1913.

30. Dang CV, O'donnell KA, Juopperi T. The great MYC escape in tumorigenesis. Cancer Cell. 2005;8(3):177-178.

31. Papaemmanuil E, Rapado I, Li Y, et al. RAGmediated recombination is the predominant driver of oncogenic rearrangement in ETV6RUNX1 acute lymphoblastic leukemia. Nat Genet. 2014;46(2):116-125.

32. Meyer N, Penn LZ. Reflecting on 25 years with MYC. Nat Rev Cancer. 2008;8(12):976990.

33. Khodabakhshi AH, Morin RD, Fejes AP, et al. Recurrent targets of aberrant somatic hypermutation in lymphoma. Oncotarget. 2012;3(11):1308-1319.

34. An G, Xu Y, Shi L, et al. Chromosome 1q21 gains confer inferior outcomes in multiple myeloma treated with bortezomib but copy number variation and percentage of plasma cells involved have no additional prognostic value. Haematologica. 2014;99(2):353-359.

35. Pasqualucci L, Compagno M, Houldsworth $\mathrm{J}$, et al. Inactivation of the PRDM1/BLIMP1 gene in diffuse large B cell lymphoma. J Exp Med. 2006:203(2):311-317.

36. Hobbs GA, Der CJ, Rossman KL. RAS isoforms and mutations in cancer at a glance. J Cell Sci. 2016;129(7):1287-1292

37. Noeparast A, Teugels E, Giron P, et al. NonV600 BRAF mutations recurrently found in lung cancer predict sensitivity to the combination of trametinib and dabrafenib. Oncotarget. 2017;8(36):60094-60108.

38. Kim SJ, Shin H-T, Lee H-O, et al. Recurrent mutations of MAPK pathway genes in multiple myeloma but not in amyloid lightchain amyloidosis. Oncotarget. 2016;7(42): 68350-68359

39. Ohgami RS, Ma L, Monabati A, Zehnder JL, Arber DA. STAT3 mutations are present in aggressive B-cell lymphomas including a subset of diffuse large B-cell lymphomas with CD30 expression. Haematologica. 2014;99(7):e105-107.

40. Valera A, Colomo L, Martínez A, et al. ALKpositive large B-cell lymphomas express a terminal B-cell differentiation program and activated STAT3 but lack MYC rearrangements. Mod Pathol. 2013;26(10):1329-1337.

41. Ding BB, Yu JJ, Yu RY-L, et al. Constitutively activated STAT3 promotes cell proliferation and survival in the activated B-cell subtype of diffuse large B-cell lymphomas. Blood. 2008;111(3):1515-1523

42. van de Donk NWCJ, Lokhorst HM, Bloem AC. Growth factors and antiapoptotic signaling pathways in multiple myeloma. Leukemia. 2005;19(12):2177-2185.

43. Brocke-Heidrich K, Kretzschmar AK, Pfeifer $\mathrm{G}$, et al. Interleukin-6-dependent gene 
expression profiles in multiple myeloma INA-6 cells reveal a Bcl-2 family-independent survival pathway closely associated with Stat3 activation. Blood. 2004;103(1): 242-251.

44. Mine S, Hishima T, Suganuma A, et al. Interleukin-6-dependent growth in a newly established plasmablastic lymphoma cell line and its therapeutic targets. Sci Rep. 2017;7(1):10188.

45. Grande BM, Gerhard DS, Jiang A, et al. Genome-wide discovery of somatic coding and non-coding mutations in pediatric endemic and sporadic Burkitt lymphoma. Blood. 2019;133(12):1313-1324

46. Zhou Y, Xu Z, Lin W, et al. Comprehensive genomic profiling of EBV-positive diffuse large B-cell lymphoma and the expression and clinicopathological correlations of some related genes. Front Oncol. 2019;9:683.

47. Menter T, Juskevicius D, Alikian M, et al. Mutational landscape of B-cell post-transplant lymphoproliferative disorders. Br J Haematol. 2017;178(1):48-56.

48. Yoon H, Park S, Ju H, et al. Integrated copy number and gene expression profiling analy- sis of Epstein-Barr virus-positive diffuse large B-cell lymphoma. Genes Chromosomes Cancer. 2015;54(6):383-396.

49. Zhu F, Wang KB, Rui L. STAT3 activation and oncogenesis in lymphoma. Cancers (Basel). 2019;12(1):19.

50. Lam LT, Wright G, Davis RE, et al Cooperative signaling through the signal transducer and activator of transcription 3 and nuclear factor- $\{k\} B$ pathways in subtypes of diffuse large B-cell lymphoma. Blood. 2008;111(7):3701-3713. 